\title{
Complete resection of pulmonary artery haemangioma on the beating heart
}

\author{
Sameh Atta ${ }^{1}$, Danilo Verdichizzo ${ }^{1}$, Rhona Taberham ${ }^{1}$, Dionisios Stavroulias ${ }^{1}$, and Antonios \\ Kourliouros $^{1}$ \\ ${ }^{1}$ Oxford University Hospitals NHS Foundation Trust
}

February 22, 2021

\begin{abstract}
Cardiac haemangiomas are rare entities and very few cases have been reported where they originate from the main arteries of the heart. We present a case of haemangioma arising from the main PA, which was completely resected with clear margins on the beating heart.
\end{abstract}

\section{Complete resection of pulmonary artery haemangioma on the beating heart}

Sameh Atta MD, Danilo Verdichizzo MD, Rhona Taberham BMBS,

Dionisios Stavroulias MD, Antonios Kourliouros PhD

Department of Cardiothoracic Surgery, Oxford University Hospitals NHS Foundation Trust, Oxford, UK

Short running title: Pulmonary artery haemangioma

Word count: 499

\section{Corresponding author}

Antonios Kourliouros PhD FRCS(CTh)

Department of Cardiothoracic Surgery

Oxford University Hospitals

Headley Way

Oxford OX3 9DU

Email: antonios.kourliouros@ouh.nhs.uk

Tel: +44(0) 1865226167

Data availability statement : Data available on request from the authors. The data that support the findings of this study are available from the corresponding author upon reasonable request.

Funding : None.

Conflict of Interest : None.

Ethical statement : Ethics approval for this study from the IRB was waived as per NHS Health Research Authority policy. 
Written informed consent was obtained from the patient for publication of these images and accompanying case presentation in line with COPE guidance. A copy of the written consent is available for review by the Editor-in-Chief of this journal on request.

\section{Abstract}

Cardiac haemangiomas are rare entities and very few cases have been reported where they originate from the main arteries of the heart. We present a case of haemangioma arising from the main PA, which was completely resected with clear margins on the beating heart.

\section{Case presentation}

A 56-year-old female was admitted to hospital with chest pain and breathlessness following percutaneous drainage of pericardial effusion. Repeat echocardiography demonstrated effusion recurrence. A pericardial window was created through left video assisted thorascocopy that drained $500 \mathrm{ml}$ of straw coloured fluid with no evidence of purulence or malignancy.

On follow-up computed tomography (CT) of the chest and dedicated CT coronary angiography (Figure 1A) a $2 \mathrm{~cm}$ extracardiac lesion was identified adjacent to the pulmonary trunk suggestive of vascular malformation. Cardiac magnentic resonance confirmed a $22 \times 28 \times 29 \mathrm{~mm}$ mass (Figure 1B) to the left side of the pulmonary trunk with no evidence of invasion into the myocardium or other cardiac structures. The lesion was positron emission tomography negative.

The decision for surgical excision was made in a multidisciplinary setting, due to diagnostic uncertainty and possibility of low-grade sarcoma. Through median sternotomy and release of dense pericardial adhesions, a $2.5 \mathrm{~cm}$ rounded para-pulmonary artery mass was excised en-block with part of the PA adventitia (Figure $2 \mathrm{~A}$ and $2 \mathrm{~B}$ ). A small feeding vessel taking origin from the vasa vasora of the pulmonary trunk was ligated. Histopathology confirmed capillary haemangioma and no evidence of malignancy. Postoperative course was short and uneventful.

\section{Conclusion}

Optimal management of the very rare PA haemangiomas is conflicting. While conservative management with watchful waiting due to their benign nature has been advocated [1], a much radical approach with resection of the mass on cardiopulmonary bypass and incorpoarating part of the PA wall has been employed by others [2]. We believe that surgical excision is essential for the purposes of diagnosis and prevention of complications but this can be safely achieved on the beating heart with similar completeness.

\section{Figure legends}

Figure 1

[1A] CT coronary angiography showing the extracardiac ovoid lesion adjacent to the pulmonary trunk with nodular peripheral enhancement.

[1B] CMR showing a well-demarcated mass to the left of the pulmonary trunk (arrow).

Figure 2

[2A] Intraoperative image showing the mass adjacent to the pulmonary conus with a small feeding vessel originating from vasa vasorum (arrow).

[2B] The capsulated mass after en-block excision compared to measuring tape.

\section{References}

1. Beebeejaun, M.Y. and R. Deshpande, Conservative management of cardiac haemangioma. Interact Cardiovasc Thorac Surg, 2011;12:517-9. 
2. Kim, I.S., et al., Hemangioma originating from the main pulmonary artery. J Thorac Dis, 2017;9:E894E898.
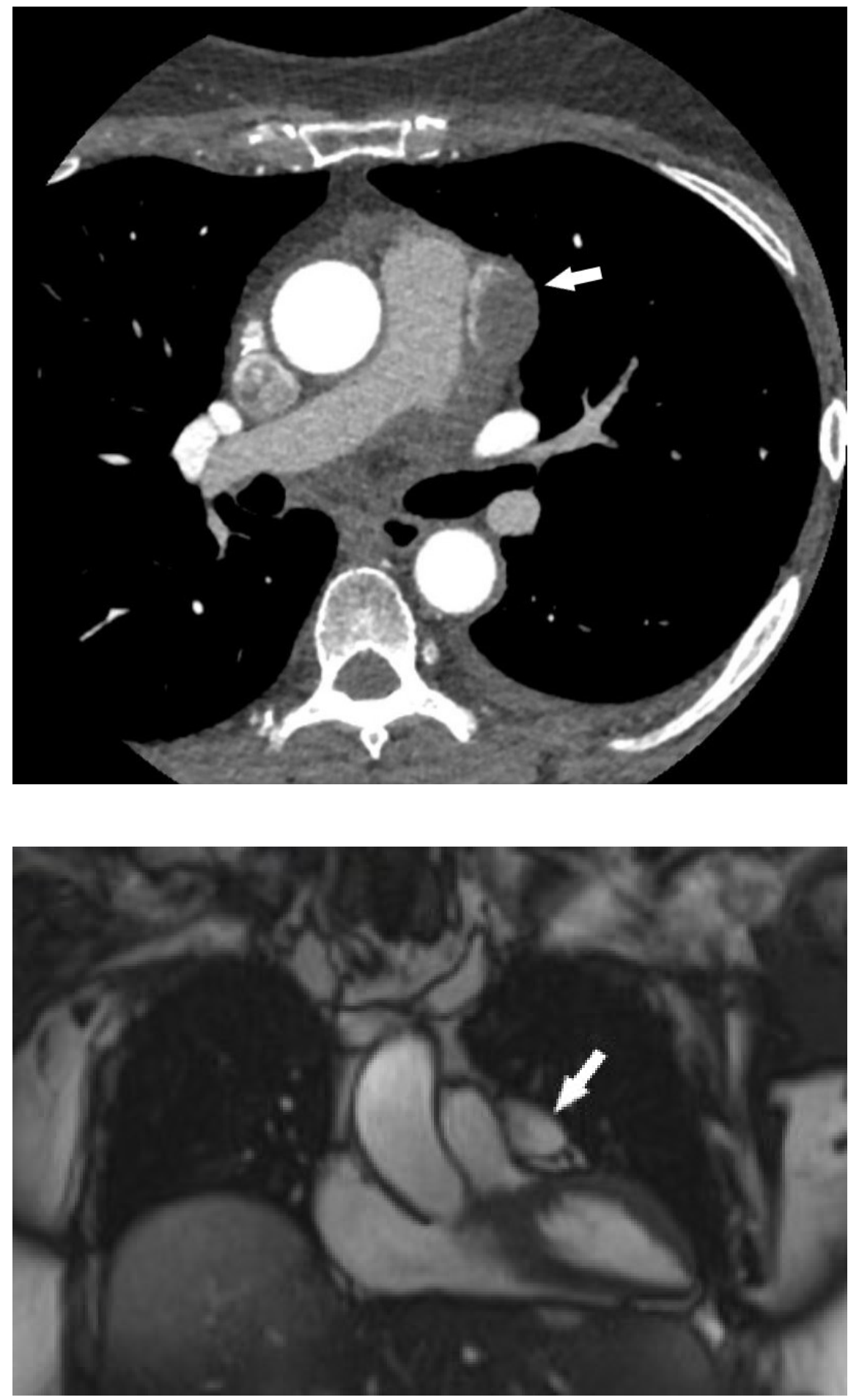


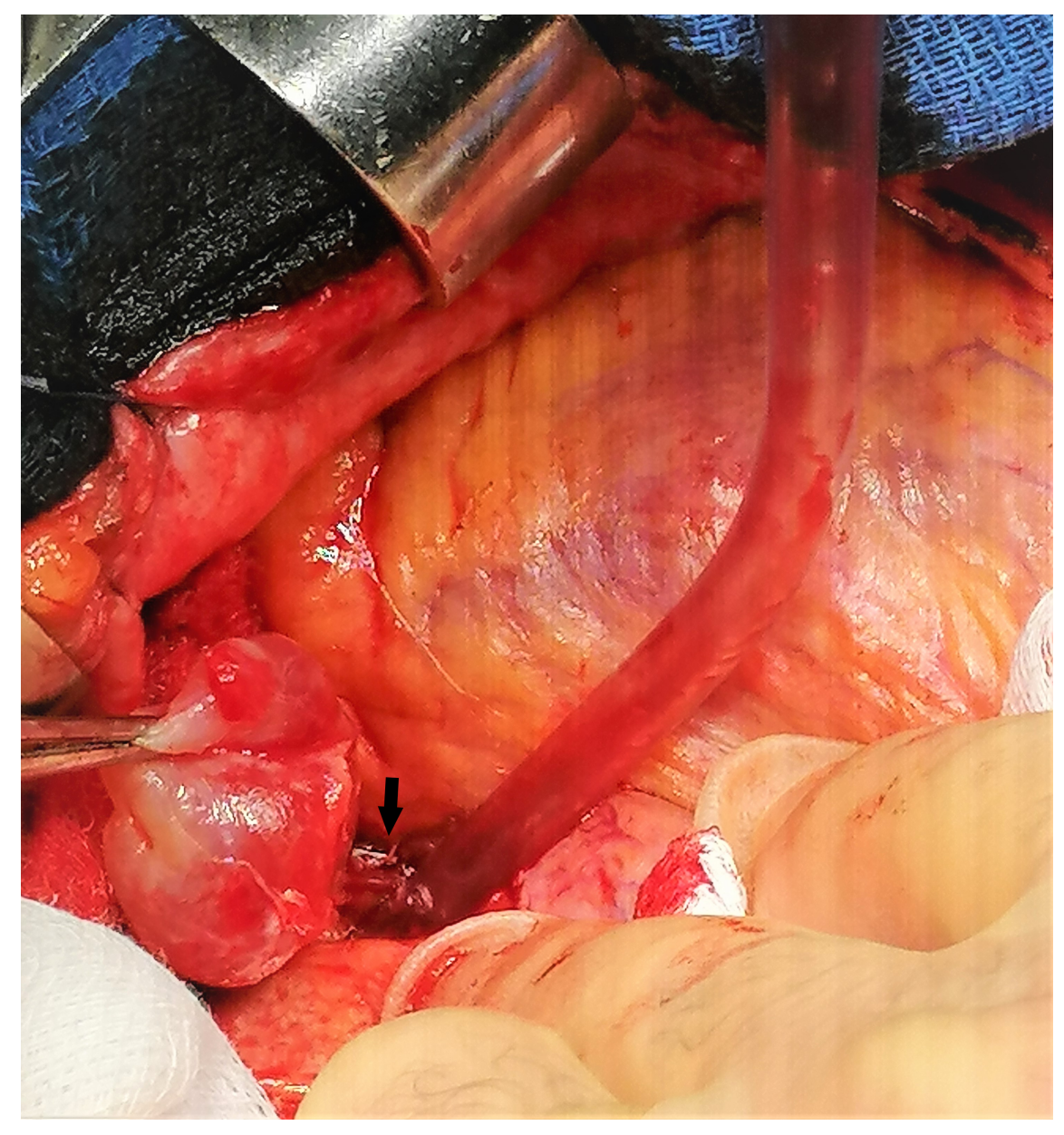




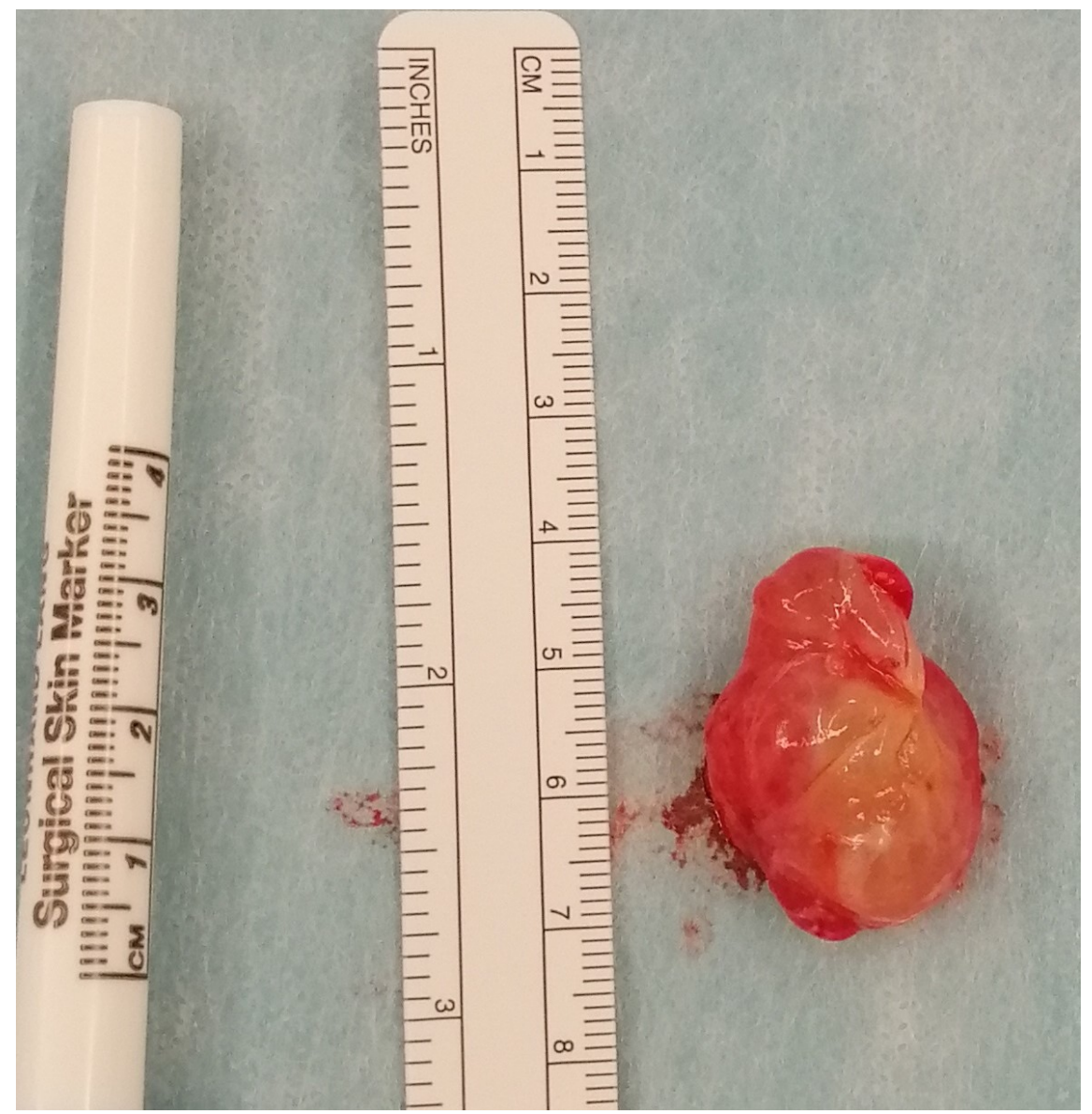

